\title{
Erratum to: Photorhabdus luminescens subsp. kleinii subsp. nov. (Enterobacteriales: Enterobacteriaceae)
}

\author{
Ruisheng An • Parwinder S. Grewal
}

Published online: 2 March 2011

(C) Springer Science+Business Media, LLC 2011

\section{Erratum to: Curr Microbiol (2011) 62:539-543 \\ DOI 10.1007/s00284-010-9741-z}

The original version of the article entitled "Photorhabdus luminescens subsp. kleinii subsp. Nov. (Enterobacteriales: Enterobacteriaceae)" (Current Microbiology, 2011, 62: 539-543) contained a statement in the first line of the last paragraph in Introduction section "In this study, symbiotic bacteria associated with Heterorhabditis georgiana strains were isolated for the first time". The correct statement should read as "In this study, symbiotic bacteria associated with three Heterorhabditis georgiana strains were isolated". Also the statement "This is also the first description of the bacteria associated with the nematode H. georgiana" in the last paragraph of Discussion section should be removed. This erratum is made due to an unintentional omission of a paper by Shapiro-Ilan et al. (2009): Characterization of biocontrol traits in the entomopathogenic nematode Heterorhabditis georgiana (Kesha strain) and phylogenetic analysis of the nematode's symbiotic bacteria (Biological Control 51: 377-387). Interestingly, the two papers report completely different subspecies of Photorhabdus luminescens to be associated with the two different strains of the same nematode species.

The online version of the original article can be found under doi:10.1007/s00284-010-9741-z.

R. An · P. S. Grewal $(\square)$

Department of Entomology, OARDC, The Ohio State University, 1680 Madison Ave, Wooster, OH 44691, USA

e-mail: grewal.4@osu.edu 